\title{
Effect of the Fuels Glycine, Urea and Citric Acid on Synthesis of the Ceramic Pigment $\mathrm{ZnCr}_{2} \mathrm{O}_{4}$ by Solution Combustion
}

\author{
Edgar Andrés Chavarriaga Miranda ${ }^{a *}$, Juan Fernando Montoya Carvajal ${ }^{a}$, \\ Oscar Jaime Restrepo Baena ${ }^{a}$ \\ ${ }^{a}$ Department of Materials Engineering, Universidad Nacional de Colombia - UNAL, \\ Calle 59A, 63-20, Medellin, Colombia
}

Received: July 9, 2015; Revised: September 12, 2015

\begin{abstract}
In this study, ceramic nanopigment $\mathrm{ZnCr}_{2} \mathrm{O}_{4}$ was prepared by solution combustion using glycine, urea and citric acid as fuels. The objective is to study the influence of fuel on the morphology and the diffuse reflectance spectrum. The nanoparticles were characterized by field emission scanning electron microscopy (FESEM), the phase was investigated by X-ray diffraction (XRD), the thermal behavior was studied by thermogravimetry analysis (TGA) and differential scanning microscopy (DSC), the color was determined by diffuse reflectance spectroscopy and CIE L*a*b* colorimetric analysis. The average crystallite sizes obtained were $18.40 \mathrm{~nm}, 42.05 \mathrm{~nm}$, and $18.69 \mathrm{~nm}$ when are used glycine, urea, and citric acid, respectively. Finally, the effect of fuel in the diffuse reflectance showed that the scattering of the light by the particles depend of the morphology. Also, the nanopigment was obtained by solution combustion at lower temperature than solid state reaction and it could be used in digital decoration.
\end{abstract}

Keywords: solution combustion, ceramic nanopigment, spinel structure, color

\section{Introduction}

Inorganic pigments are an integral part of many decorative and protective coatings, which are used for the coloration of ceramic materials including glazes, clay bodies, and porcelain enamels ${ }^{1}$. Recently, inkjet printing has been developed as a non contact direct write technology for the decoration of ceramic tiles ${ }^{2}$. The inks for inkjet printing need micro or nanosized pigment to avoid clogging the nozzle and provide excellent suspension stability. Therefore, submicron and nanosized pigments have a considerable interest in science and technology due to their high surface area, which assures a higher surface coverage and a great number of reflectance points, hence improving the scattering ${ }^{3}$.

Several authors have studied the synthesis of nanocrystalline double oxides with a spinel type cubic structure $\left(\mathrm{AB}_{2} \mathrm{O}_{4}\right)$ due to the unique potential applications, such as: magnetic materials, catalysis, cathode materials, gas sensitive materials and heat resistant pigments ${ }^{4}$. One of the most important spinels in ceramic industry is $\mathrm{ZnCr}_{2} \mathrm{O}_{4}$, which is also commonly used as magnetic material ${ }^{5}$, as humidity sensor ${ }^{6}$ and catalytic material $^{7}$, and it is synthesized by conventional solid state reaction and requires several heating and grindings steps to ensure homogeneous mixing of various oxides ${ }^{8}$. Therefore, it is important to develop new cost-effective methods to prepare $\mathrm{ZnCr}_{2} \mathrm{O}_{4}$.

The nanoparticles $\mathrm{ZnCr}_{2} \mathrm{O}_{4}$ have been synthesized by various methods including sol-gel method ${ }^{9}$, mechanical activation $^{10}$, micro-emulsion method ${ }^{11}$, precursor method ${ }^{12}$, microwave processing ${ }^{13}$, and spray pyrolysis ${ }^{14}$. Among the

*e-mail: eachavar@unal.edu.co main techniques for generating nanoparticles via the wet chemical route, solution combustion is the one that stands out. This simple technique has many advantages: homogeneous mixing, good stoichiometric control, production of active submicron-size particles in a relatively short processing time, and it involves a combustion process initiated at low temperatures, which makes use of the heat energy liberated by the exothermic reaction between fuel and nitrate ions ${ }^{15}$.

However, it has not yet been reported the influence on the color of spinel structure $\mathrm{ZnCr}_{2} \mathrm{O}_{4}$ when is synthesized by solution combustion using glycine, urea, and citric acid as fuels. Therefore, the objective of the present study was to produce ceramic nanopigments of $\mathrm{ZnCr}_{2} \mathrm{O}_{4}$ by solution combustion using glycine, urea, and citric acid as fuels, in order to evaluate the effect of the fuels on the color of the powders obtained.

\section{Experimental}

\subsection{Synthesis of powders}

The ceramic nanopigments $\mathrm{ZnCr}_{2} \mathrm{O}_{4}$ were synthesized by solution combustion using glycine, urea, and citric acid as fuels. The stoichiometric composition of the metal nitrates, and the fuels is calculated based on the total oxidizing and reducing valences of the oxidizer $(\mathrm{O})$ and fuel $(\mathrm{F})$ which serve as numerical coefficients for stoichiometric balance so that the equivalence ratio $\left(\varphi_{\mathrm{e}}\right)$ is unity, $\mathrm{O} / \mathrm{F}=1$, therefore, the energy released is at a maximum ${ }^{16}$. According to the concepts used in propellant chemistry, the elements $\mathrm{C}, \mathrm{H}, \mathrm{Zn}, \mathrm{Cu}$, $\mathrm{Cr}$, or any other metal are considered as reducing elements 
with the corresponding valencies $+4,+1,+2,+2$ and +3 (or valency of the metal ion in that compound), respectively. The element oxygen is considered as an oxidizing element with the valency -2 . The valency of nitrogen is considered to be zero. Accordingly, the oxidizing and reducing valencies of the compounds used in the combustion mixtures can be calculated.

The first experiment used $11.43 \mathrm{~g}$ of glycine $\left(\mathrm{NH}_{2} \mathrm{CH}_{2} \mathrm{COOH}\right.$, Panreac, 99\% purity), the second experiment used $13.74 \mathrm{~g}$ of urea $\left(\left(\mathrm{NH}_{2}\right)_{2} \mathrm{CO}\right.$, Carlo Erba, $99 \%$ purity), and the third experiment used $16 \mathrm{~g}$ of citric acid monohydrate $\left(\mathrm{C}_{6} \mathrm{H}_{8} \mathrm{O}_{7} * \mathrm{H}_{2} \mathrm{O}\right.$, Panreac, 99\% purity), each one of which was added to an aqueous solution of $10.4 \mathrm{~g}$ of zinc nitrate hexahydrate $\left(\mathrm{Zn}\left(\mathrm{NO}_{3}\right)_{3} * 6 \mathrm{H}_{2} \mathrm{O}\right.$, Panreac, $98 \%$ ) and $28 \mathrm{~g}$ of chromium nitrate nonahydrate $\left(\mathrm{Cr}\left(\mathrm{NO}_{3}\right)_{3} * 9 \mathrm{H}_{2} \mathrm{O}\right.$, Panreac, $\left.98 \%\right)$. The mixtures were slowly evaporated at $90{ }^{\circ} \mathrm{C}$ until gels were formed. Then, the gels were slowly heated rapidly until a vigorous self-propagating combustion reaction to obtain the powders, then the samples were calcined at $700{ }^{\circ} \mathrm{C}$ and $6 \mathrm{~h}$.

\subsection{Characterization methods}

X-Ray Diffraction (XRD) studies of the samples as-prepared and calcined were carried out using a PANanalytical X'Spert Pro X-ray diffractometer, using $\mathrm{Cu} \mathrm{K} \alpha$ radiation $(0.15406 \mathrm{~nm})$. The X-ray generator voltage was $45 \mathrm{kV}$ and the tube current was of $45 \mathrm{~mA}$, with scan step size $0.013^{\circ}$ and step time of $1.0 \mathrm{~s}$. The scanning was between $17^{\circ}$ and $69^{\circ}(2 \theta)$. The experimental diffractograms were interpreted with the help of High Score X'Spert program.

The surface morphology of polycrystalline samples of the ceramic pigments $\mathrm{ZnCr}_{2} \mathrm{O}_{4}$ were analyzed by Field Emission Scanning Electron Microscopy (FESEM) using a FESEM - JEOL JSM 6701F. The operational voltages were $12 \mathrm{kV}$ and $15 \mathrm{kV}$, and electricity current of $10 \mu \mathrm{A}$ for generating images with a working distance of $6.2 \mathrm{~mm}$. The samples were subjected to high vacuum, and coated with a layer of gold to improve its electrical conductivity.

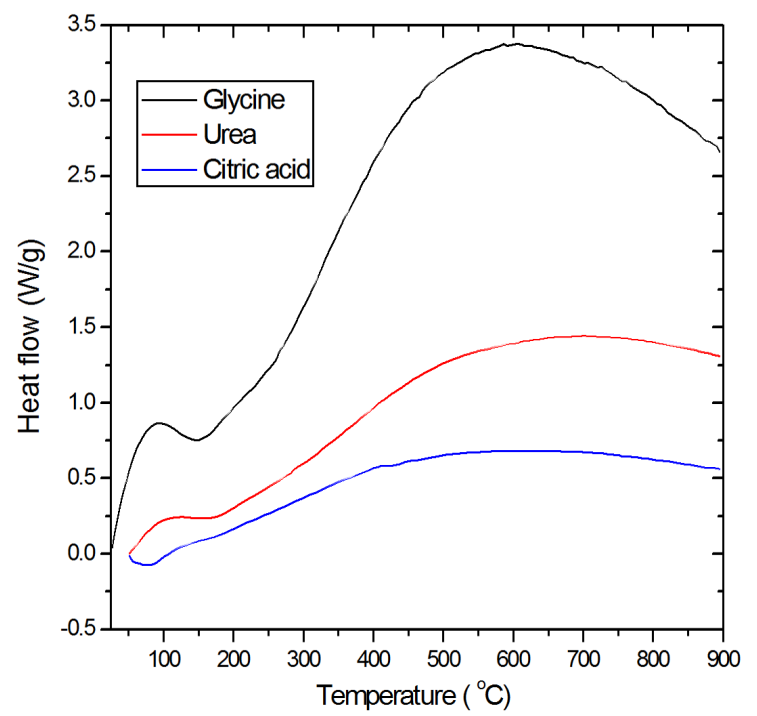

The thermal behavior of the powders was followed by thermogravimetric analysis (TGA) and differential scanning calorimetry (DSC) using Thermal Analyzer Netzsch STA $490 \mathrm{C}$. The samples were placed in an open alumina crucible and heated with a heating rate of $10{ }^{\circ} \mathrm{C} / \mathrm{min}$ from room temperature up to $900{ }^{\circ} \mathrm{C}$, under the flow of $20 \mathrm{~mL} / \mathrm{min}$ of nitrogen atmosphere.

Analysis of visible diffuse reflectance and colorimetric coordinates CIEL*a*b* of the pigments were performed on a UV-VIS spectrophotometer with spectral range 200-1050 nm. Colorimetric data were measured by combining object spectral data with data representing a CIE standard observer of $10^{\circ}$ and a CIE standard illuminant D65 (day light), as described in the standard practice ASTM E308 ${ }^{17}$. In this method, L* is the lightness axis [black (0) - white (100)], $b *$ is the blue $(-)$ and yellow $(+)$ axis, a* is the green $(-)$ and red $(+)$ axis.

\section{Results and Discussion}

Figure 1 shows the thermal analysis of differential scanning calorimetry (DSC) and thermogravimetric analysis for the samples obtained after combustion reaction between fuels and the metal nitrates. The three graphics present a similar form where an exothermic band is identified with a peak about $100^{\circ} \mathrm{C}$, which is probably due to loss of decomposition of organic matter by the sample, also another exothermic band is observed between $200{ }^{\circ} \mathrm{C}$ and $900{ }^{\circ} \mathrm{C}$, which are ascribed to organic matter that was not removed during combustion, in the literature is reported the decomposition of glycine in a nitrogen atmosphere ${ }^{18}$, which started at $250^{\circ} \mathrm{C}$ with the production of $\mathrm{NH}_{3}, \mathrm{CO}_{2}, \mathrm{H}_{2} \mathrm{O}$, a dipeptide and 2,5-piperazinedione compounds, later at $450{ }^{\circ} \mathrm{C}$ dipeptide and 2,5-piperazinedione are decomposed in $\mathrm{HNCO}, \mathrm{HCN}$, $\mathrm{CO}_{2}, \mathrm{NH}_{3}$, and $\mathrm{H}_{2} \mathrm{O}$. The results show that the products of synthesis are different, because there is a mass loss between $25{ }^{\circ} \mathrm{C}$ and $900{ }^{\circ} \mathrm{C}$ which are of $20 \%, 8 \%$, and $10 \%$ for glycine, urea, and citric acid, respectively. Therefore, there is an incomplete combustion in three cases.

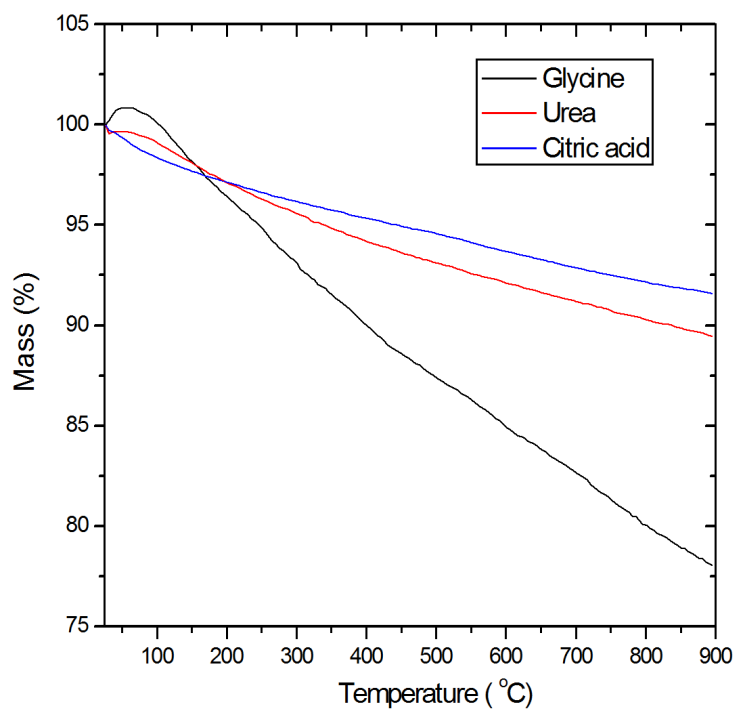

Figure 1. DSC and TG curves of $\mathrm{ZnCr}_{2} \mathrm{O}_{4}$ of the powders as prepared. 
The XRD patterns of the polycrystalline powders as-prepared and calcined in air at $700{ }^{\circ} \mathrm{C}$ and $6 \mathrm{~h}$ are shown in the Figure 2. The powders synthesized with glycine, urea, and citric acid have diffraction peaks that can be indexed well with the reference of spinel structure $\mathrm{ZnCr}_{2} \mathrm{O}_{4}$ (JCPDS 022-1107) which is a cubic crystal system with space group $\mathrm{Fd} 3 \mathrm{~m}$. Therefore, the temperatures of combustion between the fuels and metal nitrates were optimum for the formation of the pure phase. However, the samples are calcined at $700{ }^{\circ} \mathrm{C}$ and $6 \mathrm{~h}$ due to presence of organic compounds as it was shown in the thermal analysis. The Table 1 shows the average crystallite sizes of the powders as-prepared and calcined, which were determined from the full width at half maximum (FWHM) of the main intense peak (311) using Scherrer equation ${ }^{19}$. It can be seen that the calcinations of the powders at $700{ }^{\circ} \mathrm{C}$ and $6 \mathrm{~h}$ increase the sizes of the crystallites.

Figure 3 presents the FESEM micrographs of the $\mathrm{ZnCr}_{2} \mathrm{O}_{4}$ obtained by solution combustion with the fuels glycine, urea, and citric acid, which reveal agglomerated, porous, and sponge-like morphologies of the particles, these characteristics are reported in the scientific literature for the solution combustion synthesis ${ }^{20,21}$, this is due to evolution of the large amount of gaseous products during

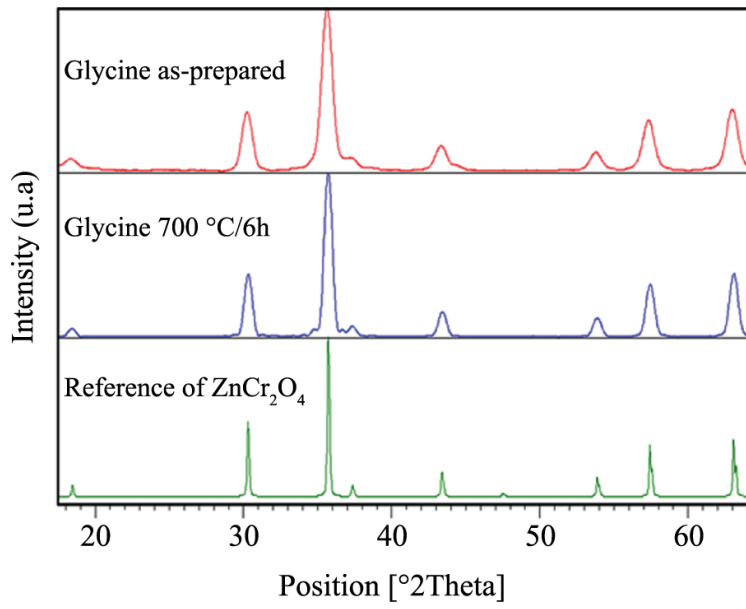

combustion, which produces highly porous voluminous powders, and these parameters dependent of fuel used in the synthesis. The glycine shows higher porous than urea and citric acid, however, it is important to note that the samples shows agglomeration of nanoparticles, but the urea shows nanometric crystals of octahedral shape of size bigger than the glycine and citric acid, which is consistent with the values calculate from XRD patterns by Scherrer equation. Therefore, these results indicate that a change in the fuel used in the synthesis lead to significant changes in the microstructure of the powders.

Figure 4 shows the diffuse reflectance factor spectrums in the range of 400-700 nm of the powders $\mathrm{ZnCr}_{2} \mathrm{O}_{4}$ synthesized by solution combustion which were annealing at $700{ }^{\circ} \mathrm{C}$ and $2 \mathrm{~h}$. The minima reflectance peaks between $420-430 \mathrm{~nm}$ and

Table 1. Average crystallite size of powders synthesized by solution combustion as prepared and calcinated.

\begin{tabular}{ccc}
\hline & as-prepared (nm) & $\begin{array}{c}\text { Calcination of } \\
\left.\mathbf{7 0 0}{ }^{\circ} \mathbf{C} / \mathbf{6 h} \mathbf{( n m}\right)\end{array}$ \\
\hline Glycine & 8.8 & 18.4 \\
Urea & 10.9 & 42.1 \\
Citric acid & 7.3 & 18.7 \\
\hline
\end{tabular}

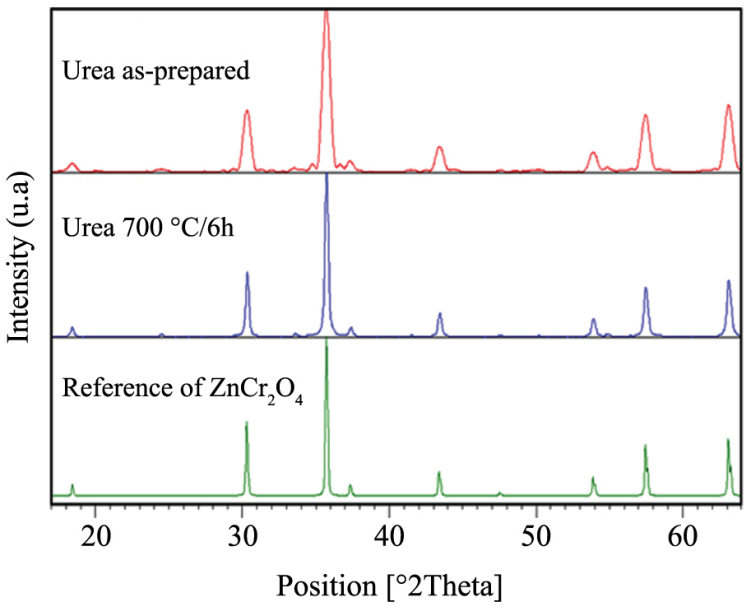

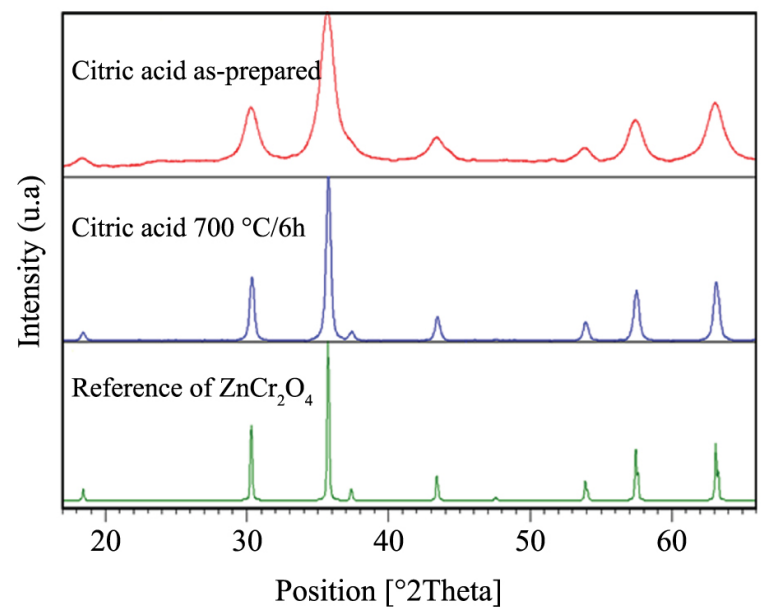

Figure 2. X-ray diffraction patterns for $\mathrm{ZnCr}_{2} \mathrm{O}_{4}$ obtained by glycine-nitrate, urea-nitrate and citric acid-nitrate. 


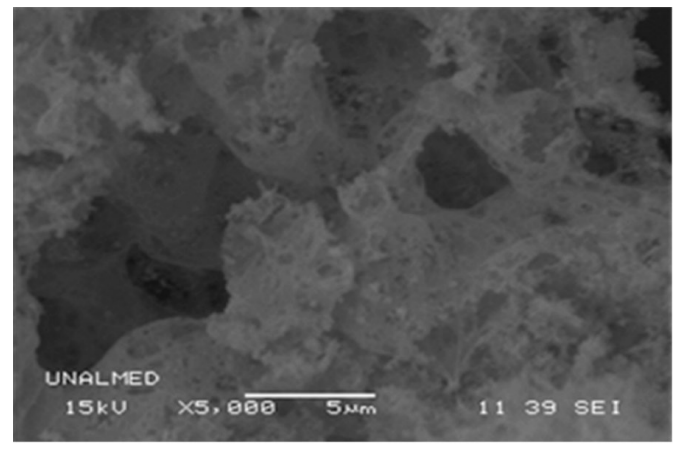

(a)

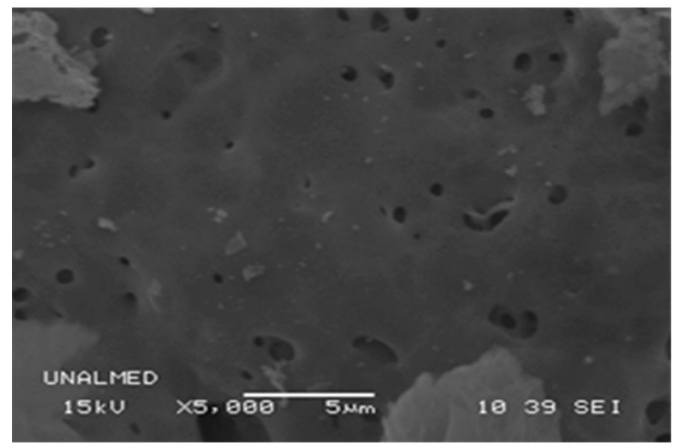

(b)

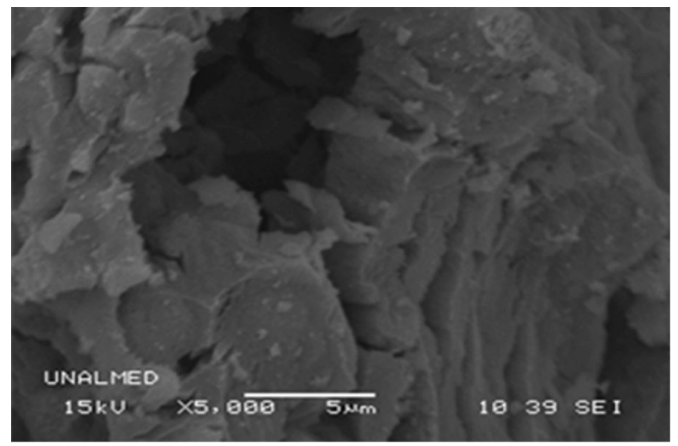

(c)

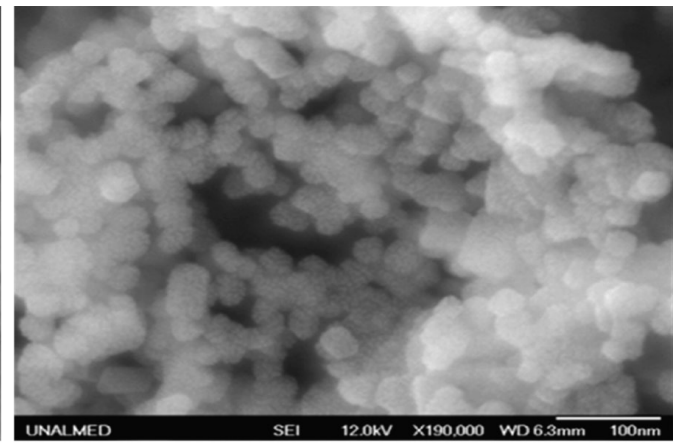

(a)

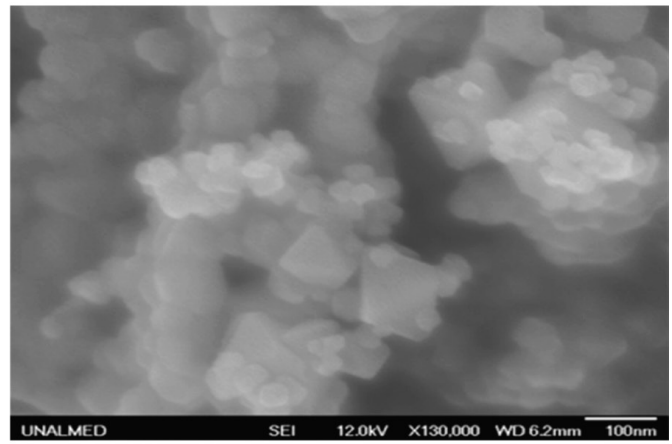

(b)

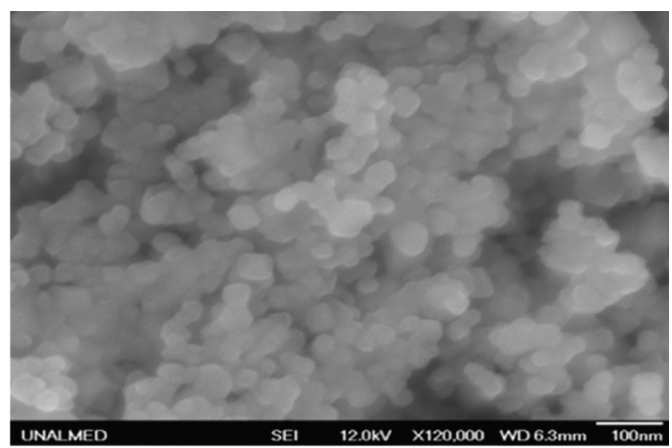

(c)

Figure 3. FESEM micrographs for $\mathrm{ZnCr}_{2} \mathrm{O}_{4}$ obtained by glycine-nitrate (a), urea-nitrate (b), and citric acid-nitrate (c).

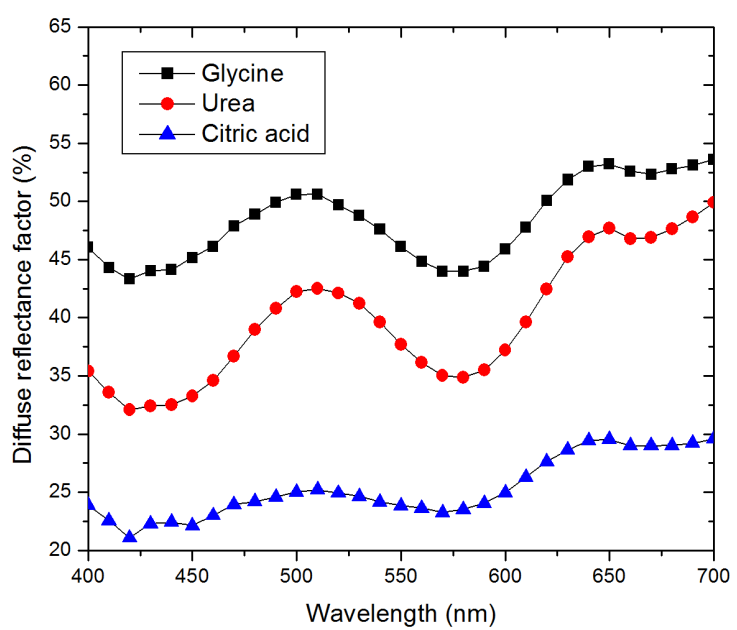

Figure 4. Visible spectrum of $\mathrm{ZnCr}_{2} \mathrm{O}_{4}$ powders.
580-600 nm can be assigned to ${ }^{4} \mathrm{~A}_{2 \mathrm{~g}} \rightarrow{ }^{4} \mathrm{~T}_{2 \mathrm{~g}}$ and ${ }^{4} \mathrm{~A}_{2 \mathrm{~g}} \rightarrow{ }^{4} \mathrm{~T}_{1 \mathrm{~g}}$ transitions of octahedral $\mathrm{Cr}(\mathrm{III})\left(\mathrm{d}^{3}\right)$ ion, respectively. These values are in good agreement with previously published data $^{22,23}$. The most important effect of the fuel in the synthesis of $\mathrm{ZnCr}_{2} \mathrm{O}_{4}$ can be appreciated in the diffuse reflectance percentages, when the glycine is used, the reflectance percentages in the visible spectrum are higher than urea and citric acid, for example with wavelength of $550 \mathrm{~nm}$, the reflectance percentages are: 50\% (glycine), 42,5\% (urea), and $25 \%$ (citric acid), these results are a consequence of the presence of volumetric defects, because at the microscopic level the loss due to bulk scattering is a result of the interaction of the electromagnetic wave with the microstructure of the sample. The total scattering loss coefficient is attributed to surface scatter, resulting from material surface imperfections, and porosity ${ }^{24}$. When glycine is used, the porosity is higher that urea and citric acid, as it was showed in the FESEM micrographs, for that reason the scattering of light increases. 
Therefore, the increase in diffuse reflectance of glycine is attributed to increase of scattering light by high porosity of the powder, due to generated gasses during the combustion reaction, whereas in the case of urea and citric acid the gasses are lower than glycine. Also, the particle size is lower in the glycine, which increases the surface area, and consequently the scattering of light also increases.

Table 2 shows the colorimetric coordinates CIEL*a*b* of $\mathrm{ZnCr}_{2} \mathrm{O}_{4}$ obtained by solution combustion, colorimetric coordinate $\mathrm{L}^{*}$ shows a higher value when is used glycine as fuel, because the scattering of the light increases due to porosity of the powder, in another way the slower value when is used citric acid as fuel, which shows the color is a function of porosity and microstructure of the samples,

Table 2. Colorimetric coordinates CIEL*a*b*

\begin{tabular}{crrc}
\hline & Glycine & Urea & Citric acid \\
\hline $\mathrm{L}^{*}$ & 74.375 & 68.647 & 56.680 \\
$\mathrm{a}^{*}$ & -1.485 & -2.814 & 0.980 \\
$\mathrm{~b}^{*}$ & 1.464 & 5.389 & 2.796 \\
\hline
\end{tabular}

\section{References}

1. Kim JH, Son BR, Yoon DH, Hwang KT, Noh HG, Cho WS, et al. Characterization of blue $\mathrm{CoAl}_{2} \mathrm{O}_{4}$ nano-pigment synthesized by ultrasonic hydrothermal method. Ceramics International. 2012; 38(7):5707-5712. http://dx.doi.org/10.1016/j.ceramint.2012.04.015.

2. Magdassi S. The chemistry of inkjet inks. Singapore: World Scientific Pub; 2010.

3. Pan Z, Wang Y, Huang H, Ling Z, Dai Y and Ke S. Recent development on preparation of ceramic inks in inkjet printinig. Ceramics International. 2015; 41(10):12515-12528. In press. http://dx.doi.org/10.1016/j.ceramint.2015.06.124.

4. Torkian L and Daghighi M. Effects of $\beta$-alanine on morphology and optical properties of $\mathrm{CoAl}_{2} \mathrm{O}_{4}$ nanopowders as a blue pigment. Advanced Powder Technology. 2014; 25(2):739-744. http://dx.doi.org/10.1016/j.apt.2013.11.003.

5. Kagomiya I, Toki M, Kohn K, Hata Y, Kita E and Siratori K. Magnetic clusters in three dimensional spin frustrated system $\mathrm{ZnCr2O4.} \mathrm{Journal} \mathrm{of} \mathrm{Magnetism} \mathrm{and} \mathrm{Magnetic} \mathrm{Materials.} \mathrm{2004;}$ 272:E1031-E1032. http://dx.doi.org/10.1016/j.jmmm.2003.12.1028.

6. Pokhrel S, Jeyaraj B and Nagaraja KS. Humidity: sensing properties of $\mathrm{ZnCr}_{2} \mathrm{O}_{4}-\mathrm{ZnO}$ composites. Materials Letters. 2003; 57(22-23):3543-3548. http://dx.doi.org/10.1016/S0167577X(03)00122-8.

7. Venugopal A, Sarkari R, Anjaneyulu C, Krishna V, Kumar MK, Narender N, et al. Influencia of acid-base sites on $\mathrm{ZnO}-\mathrm{ZnCr}_{2} \mathrm{O}_{4}$ catalyst during dehydrocyclization of aqueous glycerol and ethylenediamine for the synthesis of 2-methylpyrazine: kinetic and mechanism studies. Applied Catalysis A, General. 2014; 469:398-409. http://dx.doi.org/10.1016/j.apcata.2013.10.023.

8. Kavasoğlu N, Kavasoğlu AS and Bayhan M. Comparative study of $\mathrm{ZnCr}_{2} \mathrm{O}_{4}-\mathrm{K}_{2} \mathrm{CrO}_{4}$ ceramic humidity sensor using computer controlled humidity measurement set-up. Sensors and Actuators. A, Physical. 2006; 126(2):335-361. http://dx.doi.org/10.1016/j. sna.2005.10.049.

9. Yazdanbakhsh M, Khosravi I, Goharshadi EK and Youssefi A. Fabrication of nanospinel $\mathrm{ZnCr}_{2} \mathrm{O}_{4}$ using sol-gel method and its application on removal of azo dye from aqueous solution. the coordinates $a^{*}$ and $b^{*}$ have low values for the powder obtained using citric acid, which show low values of color, for the powders obtained using glycine and citric acid, the negative value in colorimetric coordinate $\mathrm{a}^{*}$ shows that they are green, whereas the positive value in colorimetric $b^{*}$ indicates the samples are yellow.

\section{Conclusions}

Ceramic nanopigment $\mathrm{ZnCr}_{2} \mathrm{O}_{4}$ has been synthesized by solution combustion using glycine, urea, and citric acid and it was shown that when the combustion reaction produces a great amount of gases, the porosity and the scattering of the light increases, therefore, the color of the powder change, which indicates that the final color of the powders is a function of the fuel used. Also, the nanopigments were obtained at temperatures and reaction times lower than solid state reaction, which would avoid the use of mineralizing fluxing agents for the synthesis of the pigment, in addition, the small average crystallite sizes of $18.4 \mathrm{~nm}$ (glycine), $42.1 \mathrm{~nm}$ (urea), and $18.7 \mathrm{~nm}$ (citric acid) indicate that they could be use in digital decoration.

Journal of Hazardous Materials. 2010; 184(1-3):684-689. http:// dx.doi.org/10.1016/j.jhazmat.2010.08.092. PMid:20863619.

10. Marinković Stanojević ZV, Romčević N and Stojanović B. Spectroscopic study of spinel $\mathrm{ZnCr}_{2} \mathrm{O}_{4}$ obtained from mechanically activated $\mathrm{ZnO}-\mathrm{Cr}_{2} \mathrm{O}_{3}$ mixtures. Journal of the European Ceramic Society. 2007; 27(2-3):903-907. http:// dx.doi.org/10.1016/j.jeurceramsoc.2006.04.057.

11. Niu X, Du W and Du W. Preparation and gas sensing properties of $\mathrm{ZnM}_{2} \mathrm{O}_{4}(\mathrm{M}=\mathrm{Fe}, \mathrm{Co}, \mathrm{Cr})$. Sensors and Actuators. B, Chemical. 2004; 99(2-3):405-409. http://dx.doi.org/10.1016/j. snb.2003.12.007.

12. Gingasu D, Mindru I, Culita D, Patron L, Calderon-Moreno JM, Preda S, et al. Investigation of nanocrystalline zinc chromite obtained by two soft chemical routes. Materials Research Bulletin. 2014; 49:151-159. http://dx.doi.org/10.1016/j. materresbull.2013.08.062.

13. Parhi $P$ and Manivannan V. Microwave metathetic approach for the synthesis and characterization of $\mathrm{ZnCr}_{2} \mathrm{O}_{4}$. Journal of the European Ceramic Society. 2008; 28(8):1665-1670. http:// dx.doi.org/10.1016/j.jeurceramsoc.2007.11.005.

14. Marinković ZV, Mančić L, Marić R and Milošević O. Preparation of nanostructured $\mathrm{Zn}-\mathrm{Cr}-\mathrm{O}$ spinel powders by ultrasonic spray pyrolysis. Journal of the European Ceramic Society. 2001; 21(10-11):2051-2055. http://dx.doi.org/10.1016/S09552219(01)00170-4.

15. Alves AK, Bergmann CP and Berutti FA. Novel synthesis and characterization of nanostructured materials. Berlin: Springer Verlag; 2013. http://dx.doi.org/10.1007/978-3-642-41275-2.

16. Patil KC, Hegde MS, Rattan T and Aruna ST. Chemistry of nanocrystalline oxide materials combustion synthesis, properties and applications. Singapore: World Scientific Publishing; 2008. http://dx.doi.org/10.1142/9789812793157.

17. American Society for Testing and Materials - ASTM. ASTM E308-15: standard practice for computing the colors of objects by using the CIE system. West Conshohocken: ASTM International; 2015. http://dx.doi.org/10.1520/E0308-15.

18. Manukyan KV, Cross A, Roslyakov S, Rouvimov S, Rogachev AS, Wolf E, et al. Solution combustion synthesis of nano- 
crystalline metallic materials: mechanistic studies. The Journal of Physical Chemistry C. 2013; 117(46):24417-24427. http:// dx.doi.org/10.1021/jp408260m.

19. Waseda Y, Matsubara E and Shinoda K. X-Ray diffraction crystallograpgy introduction, examples and solved problems. Heidelberg: Springer Verlag; 2011.

20. Oliveira FF, Da Dalt S, Sousa VC and Bergmann CP. Synthesis of $\mathrm{SrBi}_{2} \mathrm{Ta}_{2} \mathrm{O}_{9}$ by solution combustion and its characterization. Powder Technology. 2012; 225:239-243. http://dx.doi. org/10.1016/j.powtec.2012.04.023.

21. Costa ACFM, Silva VJ, Xin CC, Vieira DA, Cornejo DR and Kiminami RHGA. Effect of urea and glycine fuels on the combustion reaction synthesis of Mn-Zn ferrites: evaluation of morphology and magnetic properties. Journal of Alloys and
Compounds. 2010; 495(2):503-505. http://dx.doi.org/10.1016/j. jallcom.2009.10.065.

22. Gingasu D, Mindru I, Patron L, Culita D, Calderon-Moreno JM, Diamandescu L, et al. Precursor method: a non conventional route for the synthesis of $\mathrm{ZnCr}_{2} \mathrm{O}_{4}$ spinel. Journal of Physics and Chemistry of Solids. 2013; 74(9):1295-1302. http://dx.doi. org/10.1016/j.jpcs.2013.04.007.

23. Singh N and Rhee JY. Electronic structures and optical properties of spinel $\mathrm{ZnCr}_{2} \mathrm{O}_{4}$. Journal of the Korean Physical Society. 2010; 57(5):1233-1237. http://dx.doi.org/10.3938/jkps.57.1233.

24. Zhang W, Lu T, Wei N, Wang Y, Ma B, Li F, et al. Assessment of light scattering by pores in Nd:YAG transparent ceramics. Journal of Alloys and Compounds. 2012; 520:36-41. http:// dx.doi.org/10.1016/j.jallcom.2011.12.012. 